\title{
The Participation of Media in Anti-Islamic Propaganda (The Cases of Theo van Gogh and Malala Yousafzai)
}

\author{
L. M. Horodenko, D. O. Oltarzhevsky, Y. S. Tsymbalenko*, K. O. Sokolova, F. Habibi \\ Taras Shevchenko National University of Kyiv, Institute of Journalism \\ *Corresponding author. E-mail: e.tsymbalenko@knu.ua
}

Paper received 07.05.18; Accepted for publication 15.05.18.

\begin{abstract}
https://doi.org/10.31174/SEND-HS2018-169VI28-05
\end{abstract}
\begin{abstract}
The article reflects on the major cases of anti-Islamic activity (the murder of Theo van Gogh and Malala Yousafzai murder attempt) which includes certain kinds of participation. There were presented the stages that lead to stereotype formation which is used to manipulate the audience. There, propaganda is defined as irreversible stage. It doesn't have a model of audience's behavior but has a model of media activity. The main kinds of media participation in anti-Islamic propaganda were defined and systemised. Active participation includes of discrimination. Passive is about unreliable sources and biased information.
\end{abstract}

Keywords: anti-Islamic; propaganda; participation; social journalism.

Drastic changes are happening in modern media environment and social communication technologies are often used for managing public opinion. Everyone should be aware that there is effective anti-Islamic propaganda, consciously or unconsciously created and supported by media workers which was reflected in the media products chosen for this research paper.

Major cases of such propaganda date back to the time after September 11, 2001. Early 2000s were important points in modern history for Islam and Christianity. As it was stated in the book by Ian Buruma concerning the murder of Theo van Gogh, in the Netherlands people danced on the street when plane crashed into World Trade Center. It was the topic actively discussed in Europe as Muslims started to arrive there [1].

As massive Muslim migration began to bring anxiety to people in Europe and America, mass media felt like they were responsible for presenting information objectively. Instead of that, they participated in a complex process of public opinion forming which led to negative Islam image creation. Later on, this anti-Islamic media activity influenced European society which had a positive result. One of these results shows that fear of unknown changed for converting Christians to Islam and a reverse process of Muslim refusing their religion. One of the sources gives the research on this topic [2].

The major cases that were chosen for analysis in this article were the murder of Theo van Gogh by Mohammed Bouyeri (Dutch, Moroccan origin), a Dutch film director, and the attempted murder of Malala Yousafzai, a teenage Pakistani activist. Both cases had enormous impact on the world as it created an illusion that Islam is dangerous and people are not safe in their countries because of Muslims. Mass media worked so hard on proving to their audience that Muslim is a synonym of extremist.

The aim of this study is to reflect on two major cases of media participation in anti-Islamic propaganda and to systemise the kinds of this participation. The study needed different approaches to problem analysis. Only the collaboration of the scholars working with different aspects of social communications helped to achieve the main goal. The aspects of social communication problem approaches were social journalism and participation concept, propaganda transformations, network communication technologies (mass consciousness), public and social advertisement.

The tasks that were defined after the discussion: 1) to give an overview of two major cases of Islam reflection in mass media, 2) to explain media participation and its impact on mass consciousness (public opinion and stereotype formation), 3) to explain the importance of negative participation and to systemise the kinds of participation as well as its results.

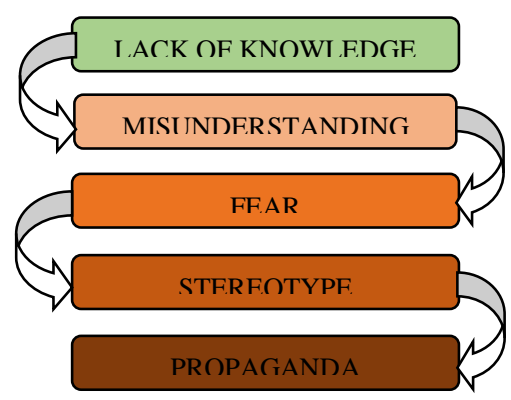

Picture 1. Stages leading to propaganda.

The methods that were used to solve the tasks: modelling (for making the schemes and media models), descriptive (for reviewing two major cases of anti-Islamic media activity, for presenting important media products on Islam related topics), analysis (for analysing the headlines, the words that were used in media products), systematization (for systemising the kind of media participation in antiIslamic media activity and its results).

Back in 2013, Kateryna Sokolova created a scheme of one of the ways of stereotypes formation [3] which included four stages: lack of knowledge, misunderstanding, fear and stereotypes formation. The work was completed as a Bachelor's thesis and only included one way. Despite that, today has perspective of becoming the base for developing or creation of a new model, e.g. adding the fifth stage of this process - propaganda based on the created stereotype (see pic. 1).

As you can see, the stages have different colours. The colour depends on the irreversibility of the processes which happen at this stage. It is necessary to stress that this research is specifically about formation of Muslim and Islamic world stereotypes.

The first stage is lack of knowledge. It is green because it can be changed by mass media in at least two ways: when the audience doesn't have all the necessary information considering a precise topic, media can add 1) more 
positive or 2) more negative facts. In the cases of Theo van Gogh and Malala Yousafzai, media were concentrated on different aspects but they were definitely adding new facts which they believed were important for final perception. Model of audience's behaviour: I don't know enough but I am ready to find out more.

The second stage is misunderstanding. It is in bright orange colour because here exists the possibility of refusing to accept new facts presented by media. It means that the audience knows something on the given topic, this information is not enough to get a full picture of what happened but it is enough for the audience to believe that all the facts are known. This stage might lead to misunderstanding of the main aspects of any problem. Model of audience's behaviour: I know enough to make conclusions on this topic.

The third stage is fear. It is in deep orange colour as it is almost irreversible. Starting from the second stage, with the lack of information and refusing to accept the facts, the person starts to fear of the unknown or, even worse, of something that they believe is true. This stage is important for anti-Islamic media activity as it is often the most visible in audience's reaction. Model of audience's behaviour: I truly believe that I know everything and it scares me.
The fourth stage is stereotype. It is in pale brown colour as it is irreversible. The only way you can change the stereotype is creating another one. Anything that is believed to be true but is not can lead to a wrong audience's perception. The stereotypes can be ruined not by adding more facts on the topic but by presenting completely new information and by creating new images. Model of behaviour: If it happens in this exact situation with this exact person of this exact religion/gender/nationality, it is definitely true for other representatives of this exact religion/gender/nationality.

The last stage is propaganda. It is in deep brown colour. It is irreversible. It is a social communications technology that is used to manipulate any audience. It is mostly used to create and support negative images. In contrary to all other stage, there is no model for audience's behaviour but there is a model of media activity: We have both positive and negative information, we choose which one to use for our benefit.

Anti-Islamic media activity can be divided into two main groups: conscious and unconscious. Each group has four kinds of activity three of which are common (see pic. 2).

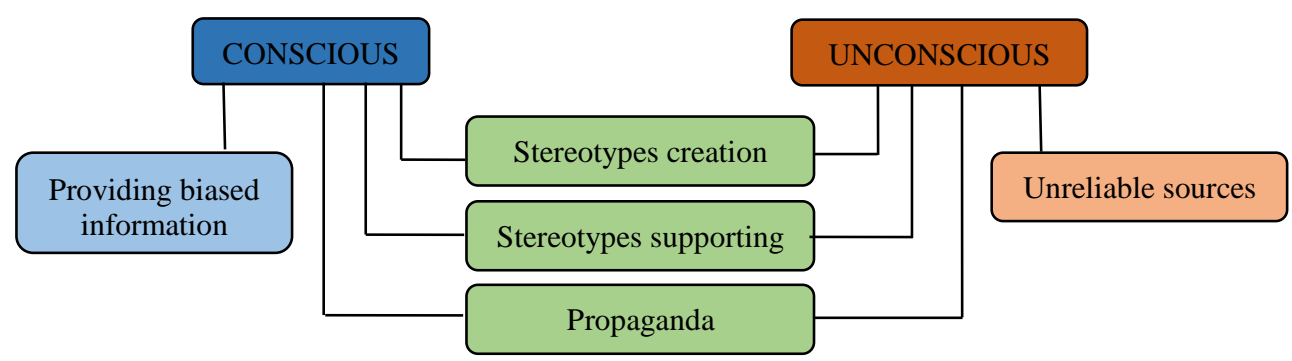

Picture 2. Anti-Islamic Media Activity (green - common, blue and brown - specific).

Both conscious and unconscious anti-Islamic media activity includes stereotypes creation, stereotypes supporting and propaganda. Conscious provides biased sources (on purpose) and unconscious provides non-checked information.

Considering different approaches to the problem, the result of anti-Islamic media activity goes through a complex process using different communication technologies (see pic. 3).

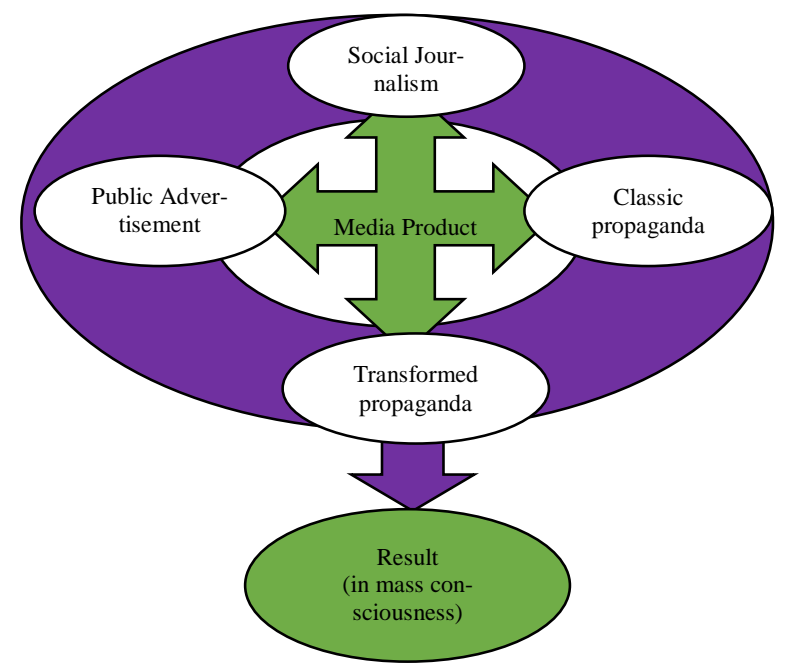

Picture 3. Result of Anti-Islamic Media Activity
In the centre of the scheme there was put a media product (with anti-Islamic main message). This product can be of social journalism (social problems/Ukrainian approach), public advertisement (involving different topics important for the society), classic propaganda (which involves authorities and official organisations, provides specialised campaigns), transformed propaganda (using new media, not official, audience-oriented and supported by that audience). Transformed propaganda becomes popular in social networks. Any person can add to anti-Islamic posts. Negativity is spread faster and gets more comments [4].

As Dmytro Oltarzhevky notices his manual "Public Advertisement" [5], can be developed in the country where everything is good or everything is bad. With the beginning of Muslim migration, people lived in a constant anxiety which leads to the creation of anti-Islamic media products.

In the first major case chosen for this article, the murder was committed in response to a provocative short film "Submission" [6] made by a Dutch director Theo van Gogh in collaboration with Dutch-Somali politician Ayaan Hirsi Ali who was actively working against Islam. The short film showed how unprotected and undervalued women can be in Islamic countries.

This film is one of the examples of public advertisement as it gives us information on one of the topics important for a certain community. It cannot be perceived as a social journalism product because it doesn't offer us a solution of the social problem (violence, gender discrimination) [7]. 
As Yevhen Tsymbalenko and Kateryna Sokolova defined [8], participation is the work of professional journalists not only with an informative component but also with practical component which involves social problems solving.

Farzana Habibi and Kateryna Sokolova stated [9] that "media products are opinion-giving and have judgmental statements considering the appearance, political and religious belongings, and activities of the media product actors." The conference presentation was prepared after media products analysis as well as two books - by Ian Buruma and Malala Yousafzai. The statement is true because in both situations media stressed on a religious background and appearance to manipulate the audience.

This brings us to the kinds of participation. In AntiIslamic media activity, they can be divided into two main groups: active and passive. Active includes discrimination whereas passive includes only unreliable sources and biased information. As you can see in pic. 2, conscious antiIslamic media activity includes biased information which is also a passive kind of participation whereas unconscious one uses unreliable sources which is also a passive kind of participation [9].

All kinds of active participation are used as mechanisms in anti-Islamic media activity (stereotypes creation, stereotypes supporting and propaganda).

All kinds of active participation are based on the appearance, religion, language, and culture. Media workers concentrate on negativities.

In Theo van Gogh's case, "a provocateur and enfant terrible of Dutch cinema" and a killer was called "a bearded man in Arab clothing" [10]. Both a murderer and a victim of the situation were characterised in a negative way.

One of the digital gaps, analysed by Lesia Horodenko [11], is a gap of free views, statements and explanation. With the creation of the space for discussions in social networks also appears a space for transformed propaganda.

Ian Buruma stated that the murder led to an aggressive public discussion and change in the attitude of people who were already noticing a large number of Muslim immigrants in the Netherlands [1].

Most of the sources were not precise about the murder attempt of Malala Yousafzai. One of the sources mentioned "officials" and the arrests without pointing out the exact names. World media published the news, focusing on the Taliban quotes without giving the exact names of their activists. All media products accented Malala's rights defending activity. Multiple sources called her a "teen activist". Right after Malala was shot, there were no precise names mentioned. Media claimed that it was Taliban giving only one possible version of everything that happened. It was obvious because Taliban also stated their involvement in the murder attempt [12]. Though, at first, they haven't specified the name of the Taliban representative.

There are six main stereotypes that are created and supported by media which were defined after analysing antiIslamic media products:

1) people of "Arabic appearance" are believed to be criminals (from pickpocketing to murders) or extremists (they come to the other countries to blow their bombs and die for their beliefs);
2) their government supports them, financing them and helps them to act against the country where they currently live;

3) they lie to get the political shelter in other countries they definitely committed crime and now they are chased by the authorities of their country;

4) they are all illegal migrants and they never work, they live on the money of tax payers of a hosting country;

5) they are aggressive, they will never help you, the cultural difference is significant, a woman who wears hijab will never understand a woman who doesn't;

6) all Muslim men are violent, they torture and hit their wives, they don't allow their wives to study, women should always stay at home and take care of children.

Using the scheme in pic. 1, it is easy to notice that most of the stereotypes from this list started from a trivial lack of knowledge. If we model a process in text it will look the following way: I don't know what hijab is. - Hijab is a thing that all Muslim women wear all the time, it covers all body. - I don't want to wear hijab. What if someone makes me to? - Muslim women are put under pressure. They should wear hijab, otherwise they will be punished or killed. It is true about all Muslim countries. - Muslim countries are dangerous for women, there is no justice, Muslim men are violent.

This is how the stage of stereotype creation is reached. The last and the most important stage (propaganda) starts when people, who truly believe in what they know, begin to use the space to free expression in new media to spread and share their thoughts with other people, who don't have their opinion formed on this topic. In this case, the arguments are effective.

The first group of people (conscious or unconscious propagandists) use one of the most influential principle of persuasion - scarcity. This principle proves that it is not enough to show what people can get, it is important to show them what they tend to lose of they don't get it. The same happens with anti-Islamic media products (classic or transformed, professional or amateur): propaganda doesn't only show who Muslim people are and how they behave, it also shows what can happen to the society where there is another religion and culture.

To conclude, a murder of Theo van Gogh and Malala Yousafzai murder attempt were two major cases which were concentrating on anti-Islamic media activity proving how dangerous Islam can be. Both cases involved information about extremists. In the first case (The Netherlands), the killer was presented by media as an extremist. Both Theo van Gogh and his murderer had negative images so they were not compared by media (no hero image) whereas Malala (Pakistan/Great Britain) was already fighting for education rights at the moment of the murder attempt. When she survived, media created and support an image of hero till present day.

Participation is important for creation on anti-Islamic media products. It can be negative which is proved by the content of the analysed media products. Negative participation can be divided into two main groups active and passive. 


\section{REFERENCES}

1. Ian Buruma, (2006). Murder in Amsterdam. The Death of Theo van Gogh and the Limits of Tolerance, 288.

2. Besheer Mohamed, Elizabeth Podrebarac Sciupac, (2018). url: http://www.pewresearch.org/fact-tank/2018/01/26/the-share-ofamericans-who-leave-islam-is-offset-by-those-who-becomemuslim/ accessed 10 May 2018.

3. Kateryna Sokolova, (2013). Reflection of the World. The Brochure about Child Refugees, 36.

4. PROFILES, (2013). What spreads faster - a negative or positive tweet? url: https://www.careerprofiles.com/blog/searchsocial/what-spreads-faster-a-negative-or-positive-tweet/ accessed 10 May 2018.

5. Oltarzhevsky, D. (2016). Sotsiana reclama [Public Advertisement]. Kyiv. Free Press Centre. 120.

6. Theo van Gogh, Ayaan Hirsi Ali, (2004). Submission, url: https://www.youtube.com/watch?v=aGtQvGGY4S4\&t=32s, accessed 2 May 2018.

7. Kateryna Sokolova, (2016). The Concept of «Social» in the Modern Journalism: Social Journalism, url https://www.academia.edu/34548759/The_Concept_of_Social_ in_the_Modern_Journalism_Social_Journalism.pdf accessed 10 May
8. Tsymbalenko, Y. \& Sokolova, K. (2016). The Participation Characteristics in the Scope of the Journalism Genres Transformations Online. Science and Education a New Dimension: Humanities and Social Sciences. IV(13), Issue 82, pp. 74-77.

9. Sokolova, K. \& Habibi, F. (2018) Anti-Islamic Media Activity. Major Cases. Mediaprostir: problem ta vyklyky siogodenja [Media Space: Problems and Challenges]. Kyiv. pp. 99-102.

10. Film-maker killed in Islamic revenge, 2004, Telegraph, url: https://www.telegraph.co.uk/news/worldnews/europe/netherlan ds/1475758/Film-maker-killed-in-Islamic-revenge.html accessed 2 May 2018

11. Horodenko, L. (2012). Tsyfrovi ta informatsiyni rozryvy v merezheviy komunikatsiji [Digital \& Information Divides in the Network Communication]. Informatsiyne suspilstvo [Information Society]. Kyiv. pp. 56-59.

12. Robert Mackey, Adam B. Ellick, (2012). Pakistani Girl Airlifted to Military Hospital, The New York Times, url: https://thelede.blogs.nytimes.com/2012/10/11/pakistani-girlairlifted-to-military-hospital/?hp accessed 15 March 2018. 